ULRICH BERGES

\title{
HACIA UNA ÉTICA DEL ANTIGUO TESTAMENTO
}

\author{
Un desafío exegético e intelectual
}

\section{Pluralidad canónica y moral autónoma}

Dar una conferencia acerca de la ética en el Antiguo Testamento en Bolivia, en un congreso acerca del tema de la interculturalidad ${ }^{1}$, parece a primera vista algo fuera de lugar. ¿En qué puede contribuir un corpus de textos tan viejo, que surgió entre los años 800 y 200 a.C., al entendimiento de la interculturalidad en nuestros tiempos modernos? La respuesta es: Este tema hace más amplia la perspectiva y muestra que la interculturalidad e internacionalidad no son sólo fenómenos de la época moderna, sino también llegan hasta los inicios de la historia cultural. Por ejemplo el tratado entre el faraón Ramsés II y el rey hitita Hattusili III del siglo XIII a.C. o los numerosos textos de tratados de los asirios y los arameos muestran que desde tiempos muy tempranos ya existían contactos internacionales y tratados de paz. En el mundo del antiguo Medio Oriente, al cual también pertenece el Israel bíblico, las fronteras territoriales no eran fronteras culturales. Pueblos, idiomas, etnias y religiones vivían en contacto intenso. El tablero de las naciones en

1 Simposio: "La Interculturalidad, un desafío actual de alcance international", 1-5 de marzo de 2015 en la Universidad Católica Boliviana "San Pablo" de Cochabamba. 
Génesis 10 nos da un indicio de lo conectado internacionalmente que se veía el Israel bíblico. La posterior historia de la torre de Babel (Gn 11) y la confusión babilónica no es un mito de la prehistoria (como por ejemplo el diluvio en Gn 6-9), sino una crítica de la ideología mesopotámica que instrumentaliza la capacidad humana de comunicación para fines imperiales.

Como lo muestran los géneros literarios del Antiguo Testamento, el Israel bíblico estaba enraizado culturalmente en su ambiente. Esto vale para los textos jurídicos (las leyes mosaicas tienen su base en los compendios jurídicos del mundo medio-oriental antiguo), para los mitos, como por ejemplo el del Paraíso, la búsqueda de la vida eterna y el diluvio (cf. Epopeya de Gilgamesh, Enuma Elish, Epopeya de Atrahasis), pero también para textos de sabiduría que tratan la pregunta del sufrimiento (ver Job y Ludlul bel nemeqi). Asimismo fue el profetismo un fenómeno del Medio Oriente Antiguo (por ejemplo: Profecías de Mari) de tal manera que los profetas del Antiguo Testamento no se pueden considerar como un caso cultural particular. No existe ningún texto en el Antiguo Testamento que no tenga sus raíces culturales en su entorno. Esto tiene consecuencias grandes para el desarrollo, la complejidad y ambigüedad del concepto de Dios de YHWH. Este también esta cargado tanto internacional como interculturalmente. Así, la idea de la justicia en forma de un sol luminoso esta acuñada por la cultura egipcia, la relación de YHWH con vendavales, tormentas y lluvias es una consecuencia de su cercanía al Baal cananeo-ugarítico. Su piedad se la debe a la deidad El y la teología de la alianza no se puede entender sin la ideología del estado asirio y su dios principal Assur. El Antiguo Testamento es verdaderamente el lugar de transición intercultural del Medio Oriente antiguo (con los reinos Egipcio, Asirio, Babilonio y Persa) al mundo griego (y con este al europeo). Dicho teológicamente: la palabra de Dios de la Biblia no es una revelación monolítica sino que surge desde un conglomerado intercultural. En lo que concierne al Nuevo Testamento, la situación es algo diferente: mientras el Antiguo Testamento se escribió en 800 años, el Nuevo Testamento, en 80. En el NT el Imperio Romano es la entidad política dominante y la idea de la cercanía del tiempo mesiánico presenta el factor teológico fundamental. Con Jesús de Nazaret empieza a realizarse el Reino de Dios y su regreso inmediato relativiza el presente. También en el NT se dejan ver grandes diferencias (véase los Evangelios sinópticos con Juan, las Epístolas Paulinas con la Epístola a los hebreos), pero el factor unificador esta en la 
persona de Cristo. ¡En el AT no se encuentra un factor semejante! Por esta razón, ¡no se debería tratar de introducir a Cristo como factor unificador en el AT porque inevitablemente esto desvaloriza a la Biblia hebrea! El AT es Palabra de Dios autónoma con valor y significado propios que no debe ser reducida a una función de preparación al evangelio (praeparatio evangelii). Desde la controversia con el herético Marción (mitad del Siglo II d.C.), la Iglesia se opuso siempre a considerar al AT como Palabra de Dios deficiente. No obstante existe hasta el día de hoy un marcionismo latente que desvaloriza la Biblia judía, que es a la vez la mas grande y primera parte de la Biblia cristiana.

Si miramos, sin prejuicios, el canon completo de las escrituras bíblicas, podemos ver una sorprendente variedad intercultural. Con la fe en Cristo Jesús las diferencias étnicas, sociales y de género no son eliminadas, pero la dicotomía, las oposiciones binarias, son superadas. Así dice Pablo en su Carta a los Gálatas: "Porque todos ustedes son hijos de Dios por la fe en Cristo Jesús, ya que todos ustedes, que fueron bautizados en Cristo, han sido revestidos de Cristo. Por lo tanto, ya no hay judío ni pagano, esclavo ni hombre libre, varón ni mujer, porque todos ustedes no son más que uno en Cristo Jesús" (Gal 3, 26-28). Pablo no habla en favor de una uniformidad, sino a favor de la unidad. La meta no es una sociedad unitaria sino el refuerzo de un lazo común, que promueve y alienta una pluralidad en la unidad con Cristo. La idea medieval de la iglesia como societas perfecta, que se ha mantenido hasta el día de hoy a través de una teología neo-escolástica, es un modelo sin futuro. El anhelo de libertad y autodeterminación no son señales del anticristo, sino que son obligaciones de personas creadas por Dios para ser libres. En resumen: La Biblia, en especial el AT, no habla un solo idioma sino que es un fenómeno cultural de muchos matices. La Biblia no es un compendio de textos unidimensional (al contrario del catecismo de la iglesia católica) sino que forma un espacio abierto de culturas e ideas variadas. Normas y reglas son validadas y rechazadas, conceptos de Dios y del hombre son discutidos a veces con muchas controversias.

Si esto es así, entonces la ética del AT no se puede limitar a justificar reglas de comportamiento con citas bíblicas (dicta probantia). Por el contrario, la ética del AT tiene la tarea de presentar este espacio 
discursivo y analizar las diferentes posiciones en él. ${ }^{2}$ La Biblia no es un manual de moral y tampoco un almacén de principios éticos. No es un autoservicio en cuyos estantes los clientes pueden servirse a diestra y siniestra según sus necesidades. Las escrituras bíblicas forman un espacio discursivo en el cual hoy en día entramos y donde encontramos muchos, (y a veces también contradictorios) argumentos y de esta manera afinamos nuestra percepción ética.

¡Lo que he dicho hasta ahora no debe ser malinterpretado como una carta blanca para un "todo vale”! ¡Al contrario: la aceptación de la pluralidad canónica y la afirmación de la autonomía moral son las dos caras de una misma moneda! El cristiano y cada persona éticamente valiente lleva consigo la responsabilidad de convertir la propia libertad en la libertad del otro. La polifonía bíblica y la diversidad cultural en nuestros países no es una carga sino un enriquecimiento. El teólogo de Münster Thomas Pröpper explica que la autonomía no significa otra cosa que la libertad es ley en sí misma y se ha dado así misma como tarea. ${ }^{3}$

\section{EI documento de la Pontificia Comisión Bíblica "Raíces bíblicas del comportamiento cristiano y esbozo de la ética del Antiguo Testamento"}

La Pontificia Comisión Bíblica publicó en 2008 el documento "Biblia y moral" en el cual se subraya el significado de las Sagradas Escrituras para la doctrina moral. No es de extrañar que el magisterio católico no se comprometa a la moral autónoma. Pero sí es de extrañar cómo el texto introduce al inicio el término de "moral revelada" $\left(\mathrm{N}^{\mathrm{o}} 4\right)$ : "En un primer tiempo, por fidelidad al movimiento de fondo de la Escritura en su totalidad, introduciremos el concepto, acaso desacostumbrado, de 'moral revelada'. Para nuestra exposición es un

2 R. KESSLER, «A Strange Land. Alttestamentliche Ethik beiderseits von Ärmelkanal und Atlantik», ThLZ 135 (2010) pp. 1307-1322; 1318.

3 Véase TH. PRÖPPER, «Autonomie und Solidarität. Begründungsprobleme sozialethischer Verpflichtungen», JCSW 36 (1995) pp. 11-26; 15: „Denn Autonomie heißt ja nichts anderes, als daß die Freiheit sich selbst Gesetz ist, sich selbst als Aufgabe gegeben. Das Phänomen ursprünglich ethischer Evidenz, also die Erfahrung unbedingter Verpflichtung läßt sich überhaupt nur auf diese Weise erklären: daß der bedingt existierenden Freiheit die Unbedingtheit des eigenen Wesens bewußt wird und sich als Anspruch geltend macht, an dem sie ihr Handeln orientieren soll." 
concepto clave. Para llegar a hablar de moral revelada, conviene liberarse de algunos presupuestos corrientes. En tanto que se reduce la moral a un código de comportamiento individual y colectivo, a un conjunto de virtudes a practicar o también a los imperativos de una ley natural considerada universal, no se puede percibir suficientemente toda la especificidad, la bondad y la actualidad permanente de la moral bíblica".

El teocentrismo del comportamiento cristiano está fuertemente marcado: La moral no se debe entender desde el punto de vista humano, sino desde el punto de vista divino. Al final del documento este concepto se repite con mucha claridad: "El hecho de basar sobre la Sagrada Escritura el conjunto de nuestra reflexión invita a considerar la moral no ante todo desde el punto de vista del hombre, sino desde el punto de vista de Dios. De aquí el concepto de 'moral revelada', que puede ser útil, si se lo comprende bien. En esto, lo hemos visto, nuestro acercamiento se distingue, desde el comienzo, de la ética y de la moral natural, fundadas esencialmente sobre la razón" ( $\left.\mathrm{N}^{\mathrm{o}} 156\right)$.

Al presentar la idea de una moral revelada, da la impresión de que los conceptos de los comportamientos presentados en la Biblia fueran diferentes a los presentados en las naciones vecinas. Esto se hace particularmente notorio en el número 9 que lleva por título "El lugar de la libertad humana". En él es representado el concepto de alianza como una idea básica de la moral revelada: "De este modo nace la moral revelada, la 'moral en situación de alianza': un don de Dios, totalmente gratuito que, una vez ofrecido, interpela la libertad del ser humano en cuanto a un sí completo, una aceptación integral: la mínima derogación sería el equivalente a un rechazo. Esta moral revelada, expresada en un marco teológico de alianza, representa una novedad absoluta respecto a los códigos éticos y culturales que regían la vida de los pueblos circundantes. Tiene, por esencia, un carácter de respuesta, sigue a la gracia, el autocompromiso de Dios". Esto no es exacto desde el punto de vista de la historia literaria y teológica pues el concepto de la alianza es un concepto político de los neo-asirios, con el cual Asur comprometió a sus vasallos a una obediencia absoluta a cambio de una garantía de protección. Entonces no se puede hablar de una novedad absoluta. Por el contrario: los teólogos de Israel, particularmente los del Deuteronomio captan un concepto político importante y lo adaptan de una manera creativa a YHWH como el señor del universo cuyo siervo Israel tiene una obligación de obediencia; y a cambio de esta, puede esperar protección y bendición. Si Israel rompiese la alianza, las consecuencias serían graves. 
¡Las maldiciones y bendiciones en Deuteronomio 28 solo se pueden entender correcta e históricamente en base a los contratos neo-asirios con los estados vasallos!

El concepto de la moral revelada no puede entenderse sin selección y jerarquización, pues matar a pedradas (Dt 21,18-21) al hijo desobediente no puede ser la voluntad de Dios revelada. ¡Según Ex 35,2 todo el que trabaje en el día del Sabbat será castigado con la muerte! El documento de la Comisión Bíblica se dio cuenta de este problema y trata de solucionarlo con una selección de pasajes que son dignos de tomarse en cuenta para una moral católica. El número 21 dice: "La revelación de esta moral se verifica en un desarrollo gradual y en el diálogo entre Dios y su pueblo. Por ello la enseñanza moral de la Biblia no puede ser reducida únicamente a una serie de principios o a un código de leyes casuísticas. Los textos bíblicos no pueden ser tratados como páginas de un sistema moral. Deben ser vistos, más bien, de modo dinámico, a la luz creciente de la revelación. Dios entra en el mundo y se revela siempre más, se dirige a las personas y les desafía a comprender más profundamente su voluntad y les capacita para seguirle siempre más de cerca. Esta luz alcanza su cenit con la venida de Cristo, que ha confirmado la enseñanza de Moisés y de los profetas (Mt 22,34-40) y ha instruido a su pueblo y a la humanidad entera con la propia autoridad ( $\mathrm{Mt}$ 28,19-20). A la luz de la plenitud de la revelación que Cristo ha traído, los cristianos pueden comprender el carácter fecundo de la revelación precedente. Lo que está escondido en la antigua dispensación se hace para nosotros evidente en la última fase de la revelación, cuando la luz de Cristo resucitado ilumina las intenciones de la revelación precedente de Dios. Así nosotros desciframos definitivamente el mensaje moral del Antiguo Testamento en la plenitud del contexto del Nuevo Testamento. Este proceso está guiado y asistido por el Espíritu Santo, que conduce los discípulos de Jesús hacia la verdad en toda su plenitud (Jn 16, 13).”

Si es que hay un desarrollo dinámico de la reflexión ética - ¿y quién querría hoy dudar de eso?- ¿quién fija las normas para lo bueno y lo malo, lo correcto e incorrecto? ¿quién decide entre lo culturalmente condicionado y lo teológicamente incondicional? Cuando San Pablo dice que las mujeres deberían llevar la cabeza cubierta -y si no lo quisieran, se deberían rapar la cabeza (1 Cor 11,6)-, es una afirmación culturalmente condicionada que no puede reclamar para si ningún valor ni general ni eterno. No solo el AT y el NT, también la teología de todos los siglos fue 
$\mathrm{y}$ es culturalmente condicionada, y en suma medida dependiente de factores sociales y políticos.

Echemos un vistazo, para finalizar con la segunda parte de mi exposición, a los esbozos de la ética del AT por mano de exégetas actuales. No hay muchos y la mayoría son escritos por colegas protestantes. La ética mas conocida del AT de los últimos 20 años es de Eckart Otto del año $1994 .^{4}$

Otto prácticamente solo toca los textos legislativos del AT, porque en ellos están presentes de manera explícita las normas y preceptos de conducta. Él defiende esta reducción con la observación de que de otra manera solo se llegarían a sistematizaciones no históricas. Para Eckart Otto una ética del AT no puede ser nunca prescriptiva. Para él solo puede ser descriptiva ya que calca los desarrollos en el AT. En su artículo publicado en la cuarta edición de la enciclopedia RGG (1999), Otto trata de enfocar todo el AT bajo una perspectiva ética, a sabiendas que las escrituras son muy distintas entre sí. No obstante, trata de descubrir una humanización que aumenta constantemente en este entreverado de distintas escrituras. Con el pasar de los siglos, el AT ha desarrollado un mayor grado de eticidad: las compilaciones de leyes en el AT siempre han tenido un cuidado creciente a no usar a otras personas para sus metas propias, sino que han querido convertir su protección en su máxima de comportamiento. Que el amor a los enemigos haya superado la enemistad, solo ha podido prevalecer gracias a la comprensión de los profetas, que YHWH supera también su ira contra la maldad en las personas. Gracias a la victoria del amor sobre la ira (Os 11,1-9), se rompe la espiral creciente de violencia. Con el sufrimiento vicario del siervo de Dios en Isaías 53 esta idea alcanza su cima en el AT: "El actuar divino es el paradigma de la superación personal humana en favor del otro en el Ethos de la solidaridad que contiene el amor al enemigo (Ex 23,4-5) y al extraño (Lev 19,34) como un amor al prójimo (Lev 19,18)".5

4 E. Oтто, Theologische Ethik des Alten Testaments (Theologische Wissenschaft 3,2), Stuttgart, 1994.

5 E. OTTO, «Art. Ethik III.1 Biblisch. Altes Testament», RGG4 2 (1999), pp. 16031606, 1605. 
Es interesante observar que tanto la sistemática eclesiástica del documento romano como también el esquema del desarrollo histórico del exegeta protestante simplemente pasan por alto una gran parte del AT. En ambos casos vale el principio: ¡lo que no está de acuerdo con el esquema, se deja al lado! En contraste con esto, en la tercera y última parte de mi exposición voy a mostrar la importancia de las escrituras del AT, justamente mediante los textos oscuros -es decir los textos que hablan de un Dios violento y injusto.

\section{Los textos oscuros de la violencia divina como un desafío de reflexión ética}

¿Cómo pueden desarrollar los siguientes textos una importancia ética? ¿Cómo pueden ellos jugar un papel en una lectura ética del AT?

- "Por eso la ira del Señor se enciende contra su pueblo: el Señor extiende su mano contra él y lo golpea. se estremecen las montañas y sus cadáveres son como basura en medio de las calles. A pesar de todo esto, no se aplacó su ira y su mano está aún extendida." (Is 5,25)

- "Por eso el Señor no perdona a sus jóvenes ni se compadece de sus huérfanos y de sus viudas, porque todo este pueblo es impío y malvado y toda boca profiere insensateces. A pesar de todo esto, no se aplacó su ira y su mano está aún extendida." (Is 9,17)

- "Sus niños pequeños serán estrellado ante sus ojos, sus casas saqueadas y sus mujeres violadas. ¡Miren! Yo suscrito contra ellos a los medos, que no estiman la plata, ni les importa el oro: sus arcos acribillarán a los jóvenes, no se apiadarán del fruto de las entrañas ni sentirán compasión por los niños.” (Is 13,16-18)

- "Pisado he yo solo el lagar, y de los pueblos nadie fue conmigo: píselos con mi ira, y hollelos con mi furor; y su sangre salpicó mis vestidos, y ensucié todas mis ropas" (Is 63,3)

Si es cierto que la idea de Dios es el criterio más importante de una ética bíblica, estos pasajes son entonces una gran carga ya que en ellos se presenta la imagen de Dios de una manera tan oscura que hasta se puede decir que la desfigura. ¿Cómo puede ser la justicia la base del acto moral, si ni siquiera YHWH se atiene a ella? O mejor dicho, recién lo hace 
después que Abraham lo exhorta a ello: “iLejos de ti hacer semejante cosa! ¡Matar al justo juntamente con el culpable, haciendo que los dos corran la misma suerte! ¡Lejos de ti! ¿Acaso el Juez de toda la tierra no va a hacer justicia? (Gen 18, 25). ¿Por qué deberíamos buscar la no violencia si Dios es capaz de cometer tan bárbaros actos de violencia? ¿Por qué debería ser la misericordia parte de la moral de los seres humanos dueños de la razón si ni siquiera YHWH la tiene para con los niños y viejos? ¿Por qué se deberían obedecer los mandamientos de Dios si el mismo Dios admite que ha dado leyes que no son buenas?: "Ya que no habían practicado mis leyes, habían despreciado mis preceptos y profanado mis sábados, y tenían la mirada puesta en los ídolos de sus padres. Incluso, llegué a imponerles preceptos que no eran buenos, y leyes que no dan la vida" (Ez 20, 24-25).

En las declaraciones eclesiásticas sobre Biblia y moral no hay lugar para semejantes textos, como tampoco en los esbozos académicos de la ética del AT. Estos pasajes están evidentemente condicionadas culturalmente pero es algo que comparten con todos los demás textos bíblicos. Si justamente de estos textos se quiere sacar una instrucción ética, el camino correcto no es el sólo reconstruirlos históricamente, sino también el deconstruirlos de alguna manera. En inglés se le llama a esta aproximación hermenéutica "reading against the grain" (es decir, leer a contracorriente). Este método pertenece al campo de reader-response criticism y aboga por un "resistant and subversive reading. Resistant reading is the refusal of the reader to 'buy' the text's dominant ideology without a fight $[\ldots]$ the interpreter's task is to identify the ideology the text is trying to sell - what principles and ideas it is attempting to foist upon us, and what we actually think of them". ${ }^{6}$

La meta de este método es identificar las estrategias inherentes del texto ("encoded strategies"), y revisar su validez y moralidad. En la exegesis feminista, el método de reading against the grain ya ha sacado a la luz muchas estrategias de texto ocultas. Una de las mas conocidas representantes de la interpretación feminista bíblica, Jo Cheryl Exum, resume esto de la siguiente manera: "Since as long as we remain within the androcentric ideology of the text, we can do no more than describe ancient men's views of women, a feminist critique must, of necessity,

6 A. DAVIES, Double Standards in Isaiah. Re-Evaluating Prophetic Ethics and Divine Justice (Biblical Interpretation Series 46), Leiden, 2000, p. 15. 
read against the grain. It must step outside of the text's ideology and consider what androcentric agenda these narratives promote". 7 Lo que vale para la exegesis feminista -es decir descubrir estrategias que favorecen la injusta dominación del varón sobre la mujer- también vale para los textos de la violencia divina. ¿Hemos que aceptar esa violencia solamente porque la fuente es Dios?

En una lectura ética del AT (y de la Biblia en general), no podemos conformarnos con esos textos que presentan a un Dios que es cruel con niños y viejos. Tampoco es suficiente el argumentar que esos textos son parte del código cultural del Medio Oriente antiguo.

Tenemos que decodificar estos textos oscuros y difíciles, tenemos que sacar a la luz lo ocultado, en especial a las víctimas olvidadas de la violencia. Esto sólo funciona si nosotros como lectores dejamos el privileging viewpoint, esto quiere decir la perspectiva dominante, donde Dios siempre exige y hace lo correcto. Andrew Davies dice acerca de esto: "There is always a temptation to presume that Yahweh's opinion is correct in all things, and to take his side in all matters. Normally, biblical authors succumb to this temptation and privilege the deity's viewpoint, assuming anyone who disagrees with him is wrong if not morally deficient. Isaiah has at times managed to resist that temptation"

Según David Clines la deconstrucción requiere de oposiciones binarias que son de uso general. Y la deconstrucción hace ver que las fronteras entre los extremos no están tan claramente marcadas. Él toma como ejemplo la oposición binaria entre esclavos y personas libres en Dt 23,15-16. Por lo general está claro que un esclavo no es una persona libre y que una persona libre es lo contrario de un esclavo. Pero el texto bíblico dice que un esclavo que huyó no debe ser entregado a su amo. El esclavo tiene mas bien el derecho de escoger y vivir donde quiera en Israel. Pero si un esclavo se convierte en persona libre simplemente por el hecho de haber huido, la esclavitud no esta abolida pero si están siendo puestos en tela de juicio sus fundamentos: "The point here is that if a slave can choose not to be a slave, the concept slavery does not exist as it once was

7 J. CH. EXUM, «The Hand that Rocks the Cradle», en: J. CH. EXUM, «Plotted, Shot and Painted. Cultural Representations of Biblical Women» (USOTS 215), Sheffield, 1996, pp. 80-100; 89.

8 DAVIES, Double Standards, p. 171. 
thought to exist, and the simple, commonsensical distinction between slave and free collapses". 9

Aplicando el concepto de la deconstrucción literaria a los textos de la violencia divina tenemos que aceptar que la opinión generalizada que YHWH siempre actúa con justicia y misericordia no cuadra con la Biblia. Dios mismo subraya en Ex 34,6 que él posee un lado oscuro: "El Señor pasó delante de él (=Moisés) y exclamó: "El Señor es un Dios compasivo y bondadoso, lento para enojarse, y pródigo en amor y fidelidad". La ira y la negatividad forman parte del concepto bíblico de Dios. Si tomamos en cuenta este aspecto, la imagen de Dios se hace ambigua. Esta ambigüedad debería aumentar nuestro escepticismo con respecto a todas las autoridades que actúan con un poder incontrolado, sin límites y sin interposición de recurso.

El descubrimiento de estructuras subliminales en las Sagradas Escrituras que glorifican la violencia llevan a agudizar la conciencia ética y reclama al exegeta una postura crítica. El resultado no es un relativismo fácil; más bien lleva a una mayor responsabilidad del individuo para decidirse por lo justo y bueno. La deconstrucción no elabora un nuevo canon de normas éticas sino que descentraliza la ética fortaleciendo al individuo con sus decisiones propias.

En Is 13,18 YHWH azuza a los Medos contra Babilonia y promete

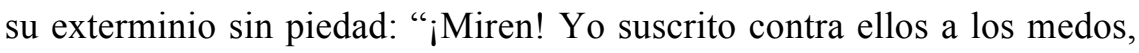
que no estiman la plata, ni les importa el oro: sus arcos acribillarán a los jóvenes, no se apiadarán del fruto de las entrañas ni sentirán compasión por los niños”. Sin duda este lenguaje violento está supeditado al contexto del Medio Oriente antiguo. ¡Pero una lectura ética no se puede conformar con esta explicación! Es la madre Sión la que culpaba a Dios mismo de haber matado a sus hijos sin misericordia: "En las calles están tendidos el niño y el anciano; mis vírgenes y mis jóvenes cayeron bajo la espada; tú has sembrado la muerte en el día de tu ira, has degollado sin piedad" (Lam 2,21). Matar o dejar matar a personas inocentes es siempre un crimen -también si Dios lo hace u ordena de hacer. La lectura ética de la Biblia no puede aceptar estándares diferentes para Dios y los hombres o sus aliados. ¿Cómo puede YHWH incriminar a los babilonios por no

9 D. J. A. CLINES, «God in the Pentateuch: Reading Against the Grain», en: D. J. A. CLINES, «Interested Parties. The Ideology of Writers and Readers of the Hebrew Bible» (JSOT.S 205), Sheffield, 1995, pp. 78-79. 
haber tenido misericordia, si el mismo actuó sin ella (véase $\mathrm{Jr}$ 6,23; 50,42)? "Yo estaba irritado contra mi pueblo profané mi herencia, y los entregué en tus manos. Tú no les tuviste compasión: hasta al anciano lo abrumaste con el peso de tu yugo" (Is 47,6). En este caso se ve claramente como YHWH mide con dos varas: lo que les estaba permitido a YHWH y a los persas, se le es reprochado a Babilonia. Aplicado al día de hoy: ¡los derechos humanos valen para todos, para amigos y enemigos igualmente!

La lectura ética de la Biblia no puede y no debe aceptar double standards, por un lado para YHWH, y por otro lado para personas, pueblos y naciones. La deconstrucción literaria hace visible las ambigüedades y afila así la conciencia moral. No mostrar misericordia con los indefensos y desprotegidos o mandar a hacerlo, es despreciable siempre y bajo cualquier condición. Si los textos oscuros del profetismo bíblico provocan semejante crítica sobre la falta de misericordia del Señor del universo, no puede haber poder terrenal alguno que se salve de recibir la misma crítica, si es que perjudica y mata a personas indefensas en nombre de la justicia que sea. No puede haber una moral bíblica o cristiana, que acepte algo en nombre de Dios que la razón moral niegue. ¡La aceptación libre y racional de normas en la Biblia tiene que ir de la mano con la resistencia igualmente libre y autónoma para con normas equivocadas en ella.

Las diferencias culturales, las muchas costumbres de los hombres no pueden eximirse de la evaluación crítica de la conciencia moral. ¿Pero qué dirige la conciencia propia? El principio más importante es la libertad, es decir una libertad que reconoce otras libertades. Esta máxima no puede depender de ninguna condición, si es que de verdad posee calidad moral. No debe degradarse a una estrategia política que dice: Reconozco tu libertad sólo si tu reconoces la mía. Por el contrario: "Justamente es la renuncia a cualquier condición, el interés de que el otro sea libre y con esto que todos sean libres; eso es lo que solamente le da al concepto de solidaridad su dignidad ética"10.

10 PRÖPPER, Autonomie und Solidarität, p. 16 („Es ist gerade dieser Verzicht auf jede Bedingung, das Interesse am Freisein und somit auch Freiwerden der Anderen, aller Anderen, was der Idee der Solidarität erst ihre ethische Dignität gibt“). 
ULRICH BERGES

ULRICH BERGES

Bonn 